\title{
Riots and a Blank Canvas: young people creating texts, creating
}

\section{spaces}

\section{Abstract}

This article draws on research into the work of Greenshoots ${ }^{1}$, a small company of creative practitioners who provide opportunities for young people to work on projects involving visual and creative practices with a strong link to local heritage. Two specific projects form the focus of the paper: Riot and Blank Canvas. Both aimed to provide opportunities for young people to work with professional artists and performers to create a site specific exhibition and performance in a disused warehouse space on the edge of the developing Creative Quarter in Nottingham. The projects took place out of school and the research focused on the creative processes and practices involved in the production of texts created by the young people as they inhabited the space and developed, within a community of peers and artists, representations of that urban space. The article explores the ways in which the projects open up the potential for young people to engage with literacy practices which traverse the boundaries of space, of art forms and of notions of culture and heritage. Two theoretical frames are used in the paper: Lave and Wenger's 'legitimate peripheral participation' (1991); and different scholars' explorations of place-based approaches. In this way, the article aims to

\footnotetext{
${ }^{1}$ All young participants referred to in this article have been anonymised and pseudonyms provided. In discussions with Greenshoots and the mentors, they took the decision that they wanted to be named and for Nottingham to be identified as the context of the place and its history is an important element of their work.
} 
contribute to understandings of the diverse roles and potentials of young peoples' creative practices and literacies in and out of school contexts.

\section{Introduction}

This article is about young people's engagement with arts and creative practices through two projects: 'Riot' and 'Blank Canvas' run by Greenshoots, a small arts and media organization in the Creative Quarter of Nottingham. Greenshoots comprises a husband and wife partnership, (Ian and Tricia Gardiner) with a very particular combination of shared experiences in the creative industries in and around the city centre. Greenshoots has worked with young people and mentored them as over time they become creative professionals within the city (usually within the Creative Quarter).The projects (which are described in more detail later in the article) involved young people of secondary school age and took place in the school holidays in a location outside of school.

This out of school context has significance as increasingly, within many neoliberal administrations, schools are finding it difficult to make space for creative and cultural activity as pragmatic choices are made about the curriculum offer in a context of increased accountability and prescription (Burnard and White 2008; Robinson 2015). Within England the pressure to meet government targets in a narrow range of prescribed academic 
subjects has led to the squeezing of arts subjects and this is particularly marked in schools in areas of high-poverty (Cairns 2013). Consequently, the status of arts and cultural activity within English schools is a subject of concern for commentators in the field (such as Cultural Learning Alliance 2015 and Robinson 2015). This is a markedly different picture to that of the early years of the new millennium when following the publication of a government commissioned enquiry (NACCCE 1999) into how young people's creativity could be better supported, the then Labour government developed policy that promoted arts and cultural activity. This led to the implementation of the Creative Partnerships programme in schools, which ran from 2002-2011 funded by the then Department for Culture, Media and Sport (DCMS) and the Department for Children, Schools and Families (DCSF), and a drive to re-develop urban areas within cities as spaces for creative activity (DCMS 2001; Roodhouse 2010).

However within the current context, in England and elsewhere, it is becoming more difficult for young people to have opportunities to engage with arts and creative projects in school, and access to the arts out of school in times of austerity is becoming a preserve of those who can have the financial means to do so (Arts Council 2014 ). It is important therefore to look at other spaces where young people are accessing opportunities to engage with the arts and to explore how young people engage with the creative organisations and practices that are on offer. 
This is the rationale for the focus of this paper about the work of Greenshoots

Greenshoots runs out of school arts projects which are freely available to young people (there is no charge for participation nor is there an audition process). These projects are well received by the young people involved, popular with their audiences and appear to have a marked impact on the young people and artists working on them, as illustrated for example, in their Facebook postings. As Kasynska argues robust evidence about the impact of arts initiatives is notoriously difficult to generate, especially when that impact is couched in economics-based discourse (2014). Finding new ways of describing and evaluating the value of arts and cultural activities is part of the debate about reframing cultural value. This is exemplified in the Performing Impact project which explored the impact of community theatre and set out 'to investigate the potential of a different set of evaluative vocabularies, which would attend more to the distinctive nature of arts practices and concentrate on processes instead of outcomes' (Thomson, Sanders, Bloomfield 2013, p. 1).

This paper, with its focus on learning and literacies in non-standard contexts and the impact on those who took part deals directly with what is emergent, divergent, often intangible and not easily observable and measurable. In acknowledging such limitations and making no claims for generalisability, the findings discussed in this paper nevertheless seek to 
illustrate and provide illuminative evidence that can be used in other arts and creative contexts.

\section{Methods}

The data for the study were generated over an eighteen month period with intense periods of research activity during school holidays when the projects were under way. The first project, Riot, lasted for six weeks whilst the second, Blank Canvas, took place nine months later and lasted for two weeks. The research focused on two groups of young people who were actively involved in the projects; there was some cross over between the sample groups as some young people from the first project also took part in the second. Riot involved around 100 young people aged between 9-17, whilst Blank Canvas involved around 25 young people aged between 11-18.

The design of the study was ethnographically motivated; that is it utilised methods associated with ethnographic studies with the aim of generating data that helped me and Greenshoots to make sense of the practices and to attempt to describe this in order to consider the pedagogical implications. The following processes formed the design of the research:

- observations of, and conversations about, ways of working with the different cohorts of young people through regular visits to the projects in process (gathering field notes, interviews, photographs and video); online data gathering: facebookFacebook, twitter, tumblr; 
- access to documentary footage of the process and other artefacts celebrating the projects.

Having spent months observing the work that goes on with the projects, it is clear to me that these projects are of value to the young people and artists involved in them. This is evidenced by the things that the young people say about their experiences and by the fact that the impact seems sustainable. I have been able to track individuals who have continued engagements with the arts either through coming back to join new projects within the same organization; or by their continued updates and contact with the group about their involvement with arts and creative projects, after they have moved onto college or university. So whilst acknowledging that there are clear limitations with the kind of data reported in this paper, evidence of the work and learning that takes place within this out of school context is edifying and potentially of interest to those exploring young people's engagement with creative and arts and literacy practices. This is particularly important to me in my role as a teacher educator with an interest in young people's learning in and out of school.

\section{Introduction to the projects: Riot and Blank Canvas}

Both projects attracted young people from a range of backgrounds and experiences. For the first project, Riot, they responded to a recruitment campaign utilising Facebook, posters and flyers in youth clubs and communities in a range of areas, and to presentations in a range of 
schools in areas of social isolation and deprivation (Offshoots 2013). This resulted in around 100 people signing up to the project; the second (smaller scale) project, Blank Canvas utilised a similar campaign (though with a shorter lead in time presentations to schools and youth clubs were not possible) and attracted around 25 people, some of whom had been involved in Riot.

Greenshoots, the organisation behind the two projects coordinates community projects that encompass film, music, drama, dance, and fashion. At the time of the Riot and Blank Canvas projects, Greenshoots had a base in a former run down manufacturing warehouse on the edges of the city's relatively newly defined Creative Quarter. They rented this space initially for six weeks to house the Riot project and raised funds through a range of activities to continue to rent the space for a further 18 months. The first few days of the Riot project involved the young people cleaning the warehouse to make it fit for purpose.

Because Greenshoots believes that their creative projects should be free for all young people, they are dependent upon bids and grants to fund the work that they do. Both projects described in this article were supported by The Heritage Lottery Fund. Other funding was made available because Greenshoots was leading a project for the National Citizen Service (NCS) project. In England, National Citizen Service involves young people coming together for three weeks to work on projects or social actions to encourage levels of citizenship amongst the young. After the riots in some 
British cities in the summer of 2011, the Prime Minister, David Cameron, extended the scheme to all 16 year olds in an effort to develop social cohesion in areas affected by the riots.

The cohort of young people for the first project was therefore made up of a group on the NCS scheme and a further group recruited by Greenshoots to join them. Greenshoots decided to encourage the young people's interest in why people rioted through a project which explored Nottingham's history of rioting. The young people spent six weeks preparing for a performance which would tell this story. The required 'social action' element of the NCS was met by planning and putting on a show to raise money for charity.

Their first job was to clean out the warehouse and then begin work on the research and preparations for the performance. As the six weeks progressed, the young people decided that the charity for their social action should be to raise funds to keep the warehouse beyond the six weeks so that other young people could benefit from similar projects.

Thus the following spring, the warehouse was stripped of all the Riot work and young people (some who had been involved in Riot) worked on a new project to create a site specific exhibition or performance in the warehouse which became a 'Blank Canvas' for their work. They researched the history of the warehouse and developed a promenade performance which would tour the four floors of the building and tell the stories of the past, present and imagined future of the space. Both 
projects involved young people actively making places for (out of school) learning.

Both projects followed the same pattern in that Greenshoots organised for the projects to be led by young local creative professionals who were establishing themselves in the Creative Quarter and who were mentored by the husband and wife team who comprise Greenshoots. Each project began with a focus on researching the local community history and utilising this research as a stimulus for stories to be re-told though performance and film.

\section{Analytical Framing}

The aim of the research was to understand how young people learn through arts and creative practices in out of school settings such as this.

The data were analysed through frequent re-reading of the interviews, field notes, social media postings, photographs and video footage. Themes and ideas arose from this re-reading and were compared with reading of associated literature during and after the data collection.

I was particularly interested in the creative practitioners' ways of working with the young people and two theoretical frames helped me to make sense of the data. These were Lave and Wenger's 'legitimate peripheral participation' (1991); and different scholars' explorations of place-based approaches based on a commitment to place, community, and place making, where place has been understood as a resource for learning (for 
example, Comber 2011, Gruenewald 2003, Massey 2005). These ideas are discussed further in the analysis that follows.

\section{A place-based approach}

Doreen Massey argues that the 'throwntogetherness' of a place, that is the way that diverse entities gather into relation in a space is what gives a place a special meaning and uniqueness; and that activities that engage people in meaning-making within that space ensure that people have a deep attachment or sense of 'belongingness' to the place (Massey 2005, p. 140). For Massey, space is not smooth flat surface; rather it is dynamic and always in the 'process of being made', the product of interactions and interrelations, characterised by multiplicity 'predicated upon the existence of plurality' of a 'myriad of stories' rather than a single linear history (ibid, p. 9). According to Massey, space is 'a simultaneity of stories so far' and 'places are collections of those stories, articulations within the wider power-geometrics of space' (ibid, p. 130). Greenshoots develops projects which involve communal arts practices and activities which revisit stories from the history of a locality. They put place at the centre of their work echoing Massey's notion of place as a 'spatio-temporal event' (2005, p. 130) that is constantly being reconfigured through the different relationships, actions and experiences that their projects bring. Greenshoots has adopted a pedagogy designed to give young people a better understanding of their community, their place and the complexity of its history. 
A place-based approach emphasises learners' relationships to places and the importance of a critical pedagogy (Gruenewald 2003). Comber and Nixon have in particular developed this idea through various explorations of ways of working which foreground the importance of allowing young people to connect with their place (for example, Comber and Nixon 2008) and the affordances of meaning-making activities with a focus on place. They argue that: 'place-based approaches to education recognize that space and place are constitutive of people's relationships and subjectivities, not static backdrops or contexts for the real action' (2012, p. 3). For Nichols, Nixon and Rowsell, the relationships between material and social aspects of places are important elements of learning within that place (2011).

With Riot this place-making involved taking the young people to different parts of their city to research Nottingham's rioting past (the Reform riots of 1831,1958 race riots, the Hyson Green 1981 riots, and the 2011 riots). They visited the castle, the Galleries of Justice (a museum based in Nottingham's old courthouse and gaol), and the streets where riots had taken place. They also visited Bromley House (a subscription library founded in 1816) and the local archive. They analysed newspapers from the past, looked at narratives and artefacts and re-storied these to create narratives to illustrate some of the individual stories behind the four Nottingham riots. They worked with music, drama, dance, fashion and film to create a show and used the site visits to help them design the sets for Riot. 
A similar approach was taken during the Blank Canvas project. The young people accessed documents from the local archive to research the history of the warehouse and discovered that it had been where the first Avery weighing machines were made. This, and the fact that it was a pre-war building that had unusually been built with a bomb shelter in the basement, formed the basis of some of the narratives that were woven into the production and performance of Blank Canvas.

Through these projects, the young people were engaging in activities which provided opportunities for interactions and encounters with different narratives and lives lived within that space across time. This 'integration of space and time' is what, Massey argues (2005, p. 130), leads to a better understanding of place. The young people were positioned both as researchers and creative practitioners who used a range of media to re-tell stories and collectively produce new texts about their city's past. They were engaging with what Barbara Comber would describe as 'creative and critical literacy pedagogies' of place (Comber, 2011). Two examples illustrate the creative and critical literacies of 'place-making' and 'text-making' (Comber, 2011).

\section{i. Valentine Marshall}

During their archival research for Riot, the local archivist told the young people the story of Valentine Marshall, a 16 year old boy, who in 1832 was found guilty of taking part in the sacking of Colwick Hall by Reform Bill rioters. Marshall maintained his innocence to the end and evidence 
against him was inconclusive with several witnesses saying he had been part of the mob whilst others said he was elsewhere at the time. The jury took just five minutes to convict him and he was sentenced to death, a sentence that was later commuted to transportation to Australia.

\section{[Insert Figure 1: Text from the local archive]}

The archivist's personal passion for this story impressed the young people: he carried a postcard in his top pocket of Valentine Marshall and a two verse poem written by Marshall describing his fate. On their visit to the former exercise yard of the gaol, they identified Marshall's name scratched into a brick wall. The injustice of the sentence and the age of the victim struck a chord and the young people worked together to write a song and a drama piece based on Valentine's story. Massey describes the process of space-time as 'weaving' layers of spatial narratives, so that '"Here'"' is an intertwining of histories in which the spatiality of those histories (their then as well as their here) is inescapably entangled' (2005, p. 139). Thus one of the young performers who played Valentine in the show observed: 'I knew so much about Valentine Marshall by the end of the project, I actually felt like him and it helped me when I was playing him in the final play.'

\section{[Insert Figure 2: Rehearsing Valentine Marshall number in the warehouse]}

ii. Reading old news

The research processes for the project involved the young people in 
careful study of past copies of local newspapers. As they looked up news articles about the riots in Nottingham they were struck by the racially biased reporting of the news in the 1950s. They wanted others to see what had angered and shocked them and used the narratives within the news stories as a basis for creating a drama piece incorporating dance and song to tell the story of the 1950 riots. When they also created a 1950s pop up café to raise funds for the show, the news stories were used to create menus on the tables. This interaction with racism and injustice in their local histories led to a series of discussions. Individuals and the group as a whole were unsettled by what they were researching. The process of creating the performance seemed to help them to work through their discomfort. For example, when preparing the 1950 s dance scene there was a discussion amongst the young people as to whether they needed an all-white and all-black group of dancers. Given the diversity of the group this was extremely challenging, especially for those who identified as mixed race. The group decision was to go for a pragmatic solution and group themselves according to height so they could partner each other in the dance; they conveyed the racial tension through the artifice of the performance rather than through 'accurate' (skin-colour) representation of the original events. This critical engagement with examples of institutional injustice from the past offers an example of place-making as 'an arena where negotiation is forced upon us' (Massey, 2005, p. 154). 


\section{[Insert Figure 3: Menu cover featuring newspaper articles]}

This approach has place at its centre and helped the young people gain a better understanding of the reasons why people had rioted in the past and why some groups of people in their city might continue to feel alienated or marginalized. According to Comber and Nixon, a key defining characteristic of a place-based approach lies in its potential to allow 'young people to connect with their places, environments and with each other' (2014, p. 86) and to provide them with a sense of agency and the belief that they can 'make a positive difference to the world' (ibid).

Through their activities and engagement with the stories of their city and the warehouse's past, the young people were actively place-making, and developing 'grounded connectedness' in the city through their work in the warehouse (Massey, 2005, p. 154). On the edge of the city's Creative Quarter the warehouse took on symbolic resonance as being 'out of place' (Cresswell 2004, p. 140) and became a safe space for them to create new associations and meanings with the city and its past. It also could be described as a third space of possibilities created when the young people and creative practitioners meet.

The warehouse space itself became the text for the next group of young people - it was literally a blank canvas as the artefacts from Riot were removed and it became a bare white space ready for the young people to re-write its narrative. Again the young people looked to the past as they researched the warehouse's history, walking around the space listening to 
the noises the building made, imagining sounds and stories from its inhabitants and eventually they came up with a multi-layered piece with stories from the past, present and future of the warehouse woven together in a promenade performance of drama, music, dance, and film.

The dancers in the basement are developing a piece, frequently pausing to hear a soundtrack that Charlie has made from recordings of sewing machines at work (linking to the facts they uncovered earlier about the warehouse's history as a sewing machine factory). Upstairs Susie is reading her rap to Scorzayzee. She explains to me that she got the idea from the security cameras on the outside wall, imagining a future where the building becomes a futuristic surveillance centre housing a robot responsible for the safety of the city with human like qualities and being unhappy with the repetitive nature of its existence. She says it's like the future would be just as repetitive as the machines from the warehouse's past. (Fieldnotes day 4, Blank Canvas).

The young people celebrated the place's past and created new interpretations of its present and its future. So this warehouse space, on the edges/borders of the Creative Quarter became a place where young people could connect with stories from their city's past, present and future and through the 'throwntogetherness' of the place 'negotiating a here-and-now (itself drawing on a history and a geography of then and theres)' (Massey 2005, p. 140). Through the creative and critical literacy 
practices they engaged with, in the space, the place became increasingly imbued with emotional connections and a very particular set of events and activities. Tuan describes this process as 'undifferentiated space' becoming 'place' as it is better understood and endowed with value (2003, p.6) and Agnew talks of the development of a greater sense of place (Agnew, 2011). Through working with narratives of the past as a cultural resource (Comber 2011), the warehouse became a meaningful place for the young people in that it represented 'a way of seeing, knowing and understanding the world. When we look at the world as a world of places we see different things. We see attachments and connections between people and place. We see worlds of meaning and experience' (Creswell 2004, p. 13).

The importance of place and of understanding of the ways meanings are constituted within and by a place through the situatedness of linguistic and semiotic signs and symbols is a key tenet of a geosemiotic approach to understanding 'discourses in place' (Scollon and Scollon 2003). Hall and Thomson mobilised geosemiotics, and in particular Scollon and Scollon's idea of a 'semiotic aggregate' in their analysis of a community arts project explaining that:

'The 'semiotic aggregate' is the composite meaning given that these systems of signs and symbols create - a fuller meaning together than the individual elements yield separately...This in our view offers a way of thinking about the potential power and value of communal 
arts activities because it encourages a focus on the people, the place, the point in time, the processes and the visual and linguistic texts in combination with one another.' (2010, p. 70-71).

The various elements of the pre-production and production activities of both projects, the visits and journeys through spaces and texts of their city played an important role in the young people's learning about their place and its real and imagined histories and comprised the 'semiotic aggregate' . These visits introduced strategic texts and interactions with these framed the basis for place making activities. Greater attachment and connection to place came from engagement and work with written texts and the creation of new spoken and performance texts. Through these varied literacy practices a sense emerged of a space 'cut through of a myriad of stories' (Massey 2005, p.9). And thus, through the projects and the final performances of both Riot and Blank Canvas, the young people were 'positioned as the researchers and witnesses of the past, who then communicated afresh the significance of that heritage to their families' (Comber 2011, p. 345). They were able to make the space dynamic, to 'make it relevant, to emphasize how important space is in the lives in which we live, and in the organization of societies in which we live' (Massey 2013, p. 2).Thus through the experiences of these arts and literacy projects, the young people became experts and advocates for their place in the city. 


\section{Legitimate peripheral participation: An apprentice model of learning with different levels of mentoring}

Lave and Wenger's 'legitimate peripheral participation' describes how newcomers become involved with a community of practice and gradually become experienced members of that community (1991). Lave and Wenger thought of learning as a situated activity and a social process. Their work has been used to analyse a range of apprenticeship-like models of learning in different communities of practice and is particularly resonant of Greenshoots' approach which has cyclical tiers of learning and mentoring involving more experienced members of the arts communities located within one specific place: the city's Creative Quarter.

For each new project, the managers of Greenshoots mentor the beginner creative practitioners as they work with young people on the project. In their work in the warehouse, the creative practitioners and the young people are engaged in what Lave and Wenger would describe as 'situated learning' (1991). Through 'legitimate peripheral participation' (which quickly involves the young people in activities central rather than peripheral to the development of the piece) they engage with real world activities within a 'community of practice' of creative professional work (1991). As the creative practitioners are mentored and in turn mentor the young people within this real community of practice, they are 
engaging in apprentice learning processes and forming their identity as creative practitioners (Fuller and Unwin 2003: 408).

This becomes cyclical, as when new projects come along some of the young people mentor the new group alongside the young creative professionals. Throughout this they are working with authenticity - young people work alongside real practitioners on a real project overseen by Tricia and Ian.

Photographs today of Emma the dancer and Ben one of the directors looking at a dance during the rehearsal stage overlooked by Ian; another of Scorzayzee (an established rap artist who Ian and Tricia supported when they ran a night club) watching the work of Charlie young music producer getting the recording mic ready for the young people. He is being helped by Dominic who was involved in the Riot project and is now learning how to mentor young musicians. Another of Nic and Ben (the directors) watched by Tricia as they choreograph the entrance from one room to another for the promenade performance. And a picture of Kate who is working with the costume designers. Also took shots of Nic and Ben with a group of scriptwriters explaining their ideas to Tricia. (Fieldnotes from day 6 Blank Canvas).

Throughout the project the young people are encouraged and required to be actively involved in the design and emerging shape of the production 
piece. The authenticity of the process seems to be important and is a contrast to what the young people have experienced in more formal learning contexts: 'with this we know we're only going to get out of it what we put into it. So we come every day and practice. We don't walk away if we can't do it [like at school]. We know it's got to be good on the night' (participant in Riot)

'Everything that you will see tonight are our ideas...'(participant in Riot during the final dress rehearsal).

\section{[Figure 4: Rehearsing the dance for the 1981 riot piece]}

Herrington and Herrington (2007) define 'authentic learning environments' as having nine key characteristics (authentic context, authentic activities, access to expert performances and models of processes, multiple roles and perspectives, collaborative construction of knowledge, reflection, articulation, coaching and scaffolding, authentic assessment) which are resonant with what was observed in Greenshoots' work in the warehouse. Vu and D'all Alba (2011) broaden this concept of authenticity 'students construct and shape what they know and can do in a process of becoming' arguing that 'this ontological dimension is central to authentic learning or, in other words, learning for authenticity, which can continue throughout life'( 2011, p. 96). Within the context of the Riot and Blank Canvas projects, young people are learning about what arts practices involve through acquiring knowledge and skills at the same time as they are becoming creative professionals. 
The effect of this process of becoming a creative artist seems to have longevity for some of the young people. The data showed that some from the Riot project re-appeared for Blank Canvas and took up a mentoring role for others. One example from the data demonstrates how informal links were maintained with Greenshoots and the positive effects of these for one young person who was going on to study film and become a filmmaker. In her interview, Sam spoke about how involvement in Riot had 'given me confidence and it has helped me to settle into university'. Through my tracking of Facebook postings after the project, I noted that during her first weeks at university, Sam frequently posted on the Greenshoots Facebook site giving updates of her experiences. Tricia responded to these posts encouraging her and reassuring her that she would find people with similar interests. A later post by Sam describes auditioning for the university's harmony group and recognising songs that she had learnt during her time on Riot. The data shows that the contact continued after that and that during Blank Canvas, a few months later, Sam visited Greenshoots, and helped out for the day with Ruby a friend she had made through Riot. She continued to post to the Greenshoots Facebook page asking members of the group to feedback on short films and videos she had made. The data from the Facebook posts shows that a few months after Riot, Ruby posted to Greenshoots explaining that she was putting on a show in her school to raise funds for a charity trip to Tanzania. The postings show that Tricia, Ian and some of the Greenshoots group of young people went along to support. It would appear that she 
had continued what had been modelled at Riot, fund raising through putting on a performance with the profits going to benefit others; utilising an arts event as a fund raiser.

\section{Conclusion}

There is evidence, across both projects, of work that deepens understanding of place and builds expertise and confidence (through legitimate peripheral participation) underpinned by a consistent pedagogy.

Through the approaches described above, the young people learn how to be artists. This is a major part of Greenshoots' ethos: to encourage young people to join the creative industries. They are trying to create a hub for young creative practitioners (who can't afford expensive city-centre rents) to have a space where they can explore their work surrounded by peers or others who are slightly further ahead in the journey.

The young people learn more about their place or community expressed through the media or form of what it is they are learning to do. Their investment in the local history of their place leads to empowerment, and a greater understanding of what Holland and Lave (2001) describe as 'history in person' as the young people identify with situated local stories and struggles through the cultural production of the shows.

This study has aimed to demonstrate the diverse roles and potentials of young peoples' literacies in and out of school contexts. Greenshoots' arts 
and literacy practices are forms of 'productive pedagogies' (Hattam, Brennan, Zepin and Comber 2009) and offer a model for similar projects in other out of school learning environments. This is a model which is based on authentic arts-based learning experiences where young people are creating texts, reading signs, engaging with the artefacts of a place and actively making a place for themselves and for others like them.

There are ways in which this approach can inform literacy and arts practices within school. Classroom-based activities which encourage students to research and explore the stories of their place, especially when these are projects that have resonance with a real community issue, allow students to engage in place-making. There emerges from this study a strong sense of celebrating the local through activities which use place as a resource for learning. If classrooms are spaces where students are actively learning by doing, through for example collaborative reconstruction of community stories into new art forms for (real) new audiences, then students will be text-making, working with authenticity, developing agency, and connecting to their place.

Models of productive pedagogies, such as those described above, are especially important in a context where opportunities to engage with similar practices are being reduced in many schools. This is because schools are focused, for the reasons outlined earlier in the introduction to this article, on a technicised approach and the meritocracy of results. At the same time, art and literacy practices such as those examined here are 
being squeezed out of the school curriculum (Barker 2015). Whilst the standards discourse is about narrowing the gap, the processes for doing so are divisive as schools serving communities of social and economical disadvantage are more pressurised to meet the performativity agenda (Vaughan 2015) than those in more affluent areas. Arts practices are becoming the preserve of those young people whose parents have the social and economic capital to support engagement with arts and culture (PCAH 2011). Greenshoots and other out of school learning communities have a real part to play in redressing this through providing opportunities for young people to engage in arts-based projects with a focus on critical literacy development. There is an element of a social justice imperative for them to do so. With their commitment to arts and creative projects being freely available for young people, Greenshoots are, for some of the young people in this study, acting as gatekeepers to this world - and in this specific context to the Creative Quarter of Nottingham so that young people can begin to see the creative and cultural spaces within the city as theirs.

\section{References}

Agnew, J. (2011) Space and place in J. Agnew and D. Livingstone (eds.) Handbook of Geographical Knowledge. London: Sage, 2011pp 316-331. 
Arts Council (2014) Create: A journal of perspectives on the value of art and culture, http://www.artscouncil.org.uk/media/uploads/value-sotacreate/Create Digital Singles V1.pdf accessed on August 25th 2015.

Burnard, P. and White, J. (2008). Creativity and performativity: counterpoints in British and Australian education. British Educational Research Journal. 34, 5, 667-682.

Barker, I. (2015). Arts 'squeezed out of state school' says private school head,Times Education Supplement, $20^{\text {th }}$ November 2015, https://www.tes.com/news/school-news/breaking-news/arts-squeezedout-state-schools-says-private-school-head accessed on December $16^{\text {th }}$ 2015.

Cairns, S. (2013). English Baccalaureate Research, Cultural Learning Alliance, http://www.culturallearningalliance.org.uk/evidence accessed June $20^{\text {th }} 2015$.

Comber, B. (2011). Making Space for Place-Making Pedagogies:

stretching normative mandated literacy curriculum. Contemporary Issues in Early Childhood, 12, 4, 343-348.

Comber, B. and Nixon, H. (2008). Spatial Literacies, Design Texts, and Emergent Pedagogies in Purposeful Literacy Curriculum, Pedagogies: An International Journal, 3:4, 221-240.

Comber, B and Nixon, H. (2014) Critical literacy across the curriculum: learning to read, question and rewrite designs, In Pandy, J. \&, Ávila, J. 
(Eds). Moving Critical Literacies Forward: A New Look at Praxis Across Contexts New York: Routledge, pp 83-98.

Creswell, T. (2004). Place: a short introduction. Oxford: Blackwell.

Department For Culture, Media And Sport (DCMS). (2001). Culture and Creativity: the Next Ten Years. London: DCMS.

Cultural Learning Alliance. (2015).

http://www.culturallearningalliance.org.uk/ accessed on December $12^{\text {th }}$ 2015 .

Fuller, A and Unwin, L. (2003). Learning as apprentices in the contemporary UK workplace: creating and managing expansive and restrictive participation, Journal of Education and Work, 16, 4, 407-426.

Gruenewald, D.A. (2003) The Best of Both Worlds: a critical pedagogy of place, Educational Researcher, 32(4), 3-12.

Hall, C. and Thomson, P. (2010), Grounded literacies: the power of listening to, telling and performing community stories. Literacy, 44: 6975.

Hattam, R., Brennan, M. , Zipin, L. \&Comber, B. (2009) Researching for social justice: contextual, conceptual and methodological challenges, Discourse: Studies in the Cultural Politics of Education. 30, 3, 303-316. Herrington, A.J. \& Herrington, J.A. (2007). What is an authentic learning environment? In L.A. Tomei (Ed), online and distance learning: Concepts, 
methodologies, tools, and applications (pp. 68-77). Hersey, PA:

Information Science Reference.

Holland, D. \& Lave, J. (2001) (Eds) History in person. Santa Fe: School of American Research Press.

Kaszynska, P. (2014) Happiness or art?

http://www.artsprofessional.co.uk/magazine/275/article/happiness-or-art accessed on October 6th 2015.

Lave, J. and Wenger, E. (1991). Situated learning: legitimate peripheral participation. Cambridge: Cambridge University Press.

Massey, D. (2005) For Space. London: Sage.

National Advisory Committee on Creative and Cultural Education. (1999). All Our Futures: Creativity, Culture and Education. London: DFEE.

Nicols, S., Nixon, H. \& Rowsell, J. (2011). Guest Editors' Introduction to the Special Issue of JECL on the Geosemiotics of Early Childhood Literacy, journal of Early Childhood. 11 (2), 107-113.

Offshoots, (2013). Young Roots: Offshoots. (Unpublished evaluation report to Heritage Lottery).

PCAH President's Committee on the Arts and the Humanities. (2011). Reinvesting in Arts Education: Winning America's Future Through Creative Schools (Washington, DC, May 2011). 
Roodhouse, S. (2010), Cultural quarters: principles and practice. Bristol: Intellect.

Robinson, K. and Aronica, L. (2015). Creative Schools: Revolutionizing Education from the Ground Up. Penguin (Allen Lane): Harmondsworth.

Scollon, R and Scollon, S.W. (2003). Discourses in place: language in the material world. Routledge: London.

Thomson, P. Sanders, J. Bloomfield, J. (2013) Performing impact: a scoping study of the ways in which community theatre understands and evaluates its work. Final Report.

https://performingimpactproject.wordpress.com/2013/03/31/our-finalreport/ accessed on October 6th 2015.6/10/15.

Tuan, Y. (2003). Space and place: the perspective of experience. Minneapolis: University of Minnesota Press.

Vaughan, R. (2015). Creative subjects sidelined in response to new league table measure, The Times Educational Supplement, $6^{\text {th }}$ March 2015, https://www.tes.com/news/school-news/breaking-news/creativesubjects-sidelined-response-new-league-table-measure accessed on 16th December 2015.

Vu, T. T., \& Dall'Alba, G. (2011). Becoming authentic professionals:

Learning for authenticity. In "Becoming" a Professional (pp. 95-108). Springer Netherlands. 